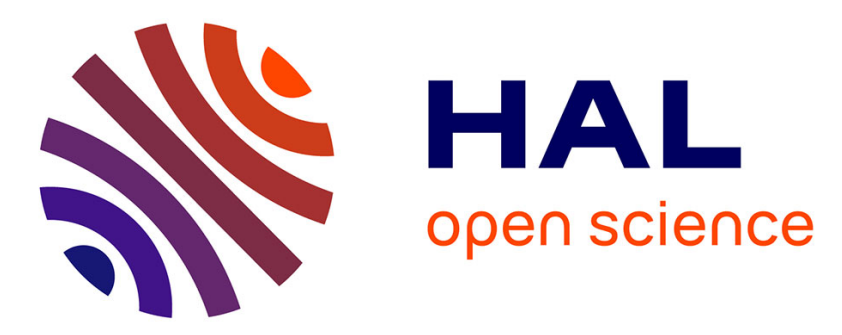

\title{
Organo-modified mesoporous silicas for organic pollutant removal in water: Solid-state NMR study of the organic/silica interactions
}

Niki Baccile, Florence Babonneau

\section{- To cite this version:}

Niki Baccile, Florence Babonneau. Organo-modified mesoporous silicas for organic pollutant removal in water: Solid-state NMR study of the organic/silica interactions. Microporous and Mesoporous Materials, 2008, 110 (2-3), pp.534-542. 10.1016/j.micromeso.2007.06.056 . hal-01455112

\section{HAL Id: hal-01455112 \\ https: / hal.sorbonne-universite.fr/hal-01455112}

Submitted on 3 Feb 2017

HAL is a multi-disciplinary open access archive for the deposit and dissemination of scientific research documents, whether they are published or not. The documents may come from teaching and research institutions in France or abroad, or from public or private research centers.
L'archive ouverte pluridisciplinaire $\mathbf{H A L}$, est destinée au dépôt et à la diffusion de documents scientifiques de niveau recherche, publiés ou non, émanant des établissements d'enseignement et de recherche français ou étrangers, des laboratoires publics ou privés. 
IMPORTANT NOTE : Please be aware that slight modifications occurring after Proof correction may occur between this version of the manuscript and the version on the Publisher's website

Organo-modified mesoporous silicas for organic pollutant removal in water: solid state NMR study of the organic/silica interactions.

Niki Baccile, ${ }^{* a, b}$ Florence Babonneau ${ }^{a}$

${ }^{a}$ LCMCP - Université Pierre et Marie Curie-Paris6; CNRS, 4 place Jussieu, 75005

Paris, France. Tel: +33 1442740 75; E-mail: baccile@ccr.jussieu.fr

${ }^{\mathrm{b}}$ Present address : Institut Charles Gerhardt Montpellier, Equipe MACS UMR 5253

CNRS/UM2/ENSCM/UM1, 8, Rue de l’Ecole Normale , 34296 Montpellier Cedex 5, France. Tel: +33467163454

\title{
Keywords
}

Hydrid organic-inorganic, mesoporous silica, functionalization, environmental, solid state NMR

\begin{abstract}
The adsorption properties of various organo-modified mesoporous silicas towards a methoxy- modified chlorophenol in water have been studied. Phenyl, propyl, hexyl and hexadecyl groups were selected to study the possible interactions that the pollutant could preferentially develop with the surface sites. The best performing sample appears to be the hexyl-modified porous silica and one of the least performing, the un-modified mesoporous silica. The physical state of the adsorbed chlorophenol in these two confined environments as well as the pollutant/surface interactions were characterized
\end{abstract}


by a combination of solid-state NMR techniques. The ${ }^{1} \mathrm{H}$ and ${ }^{13} \mathrm{C}$ NMR responses show a high mobility of the molecules in both the modified and un-modified silica, suggesting the absence of strong interactions between the pollutant and the surface, despite the large difference in the chemical nature of the silica surface sites.

\section{Introduction}

Long-range ordered mesoporous silica powders have been at the centre of interest within the material science community for the past 15 years [1]. Their structural characteristics (high surface area; tunable geometry of the porous network; narrow pore size distribution) [2] combined with the possibility to process them in various shapes [3] (calibrated spherical powders [4], thin films [5], membranes, monoliths [6]) make them extremely attractive for a wide range of applications in the fields of catalysis $[7,8,9]$ chromatography [10], drug release [11], sensors [12] or electronics [13]. The possibility to introduce a large variety of organic pendant groups to modulate the surface properties is another interesting advantage of such materials, which was first demonstrated using a one-pot synthesis route by Burkett et al. [14] and Macquarrie [15].

Very recently, the European community policy has been extremely concerned by environmental issues [16]. Indeed, mesoporous silica-based materials can find interesting applications in the field of environmental science and especially in the development of filters both for air and water treatment. Three main pathways have been so far explored: 1) materials for VOC (Volatile Organic Compounds) adsorption; 2) materials for POP (Persistant Organic Pollutant) adsorption; 3) materials for toxic metal adsorption. Examples regarding VOCs were given by G.Q. Lu et al. [17] and Serrano et al. [18]. The first one showed that a MCM-41 matrix was more efficient than activated carbon, zeolite T and silicalite-1 materials with respect to benzene, carbon tetrachloride 
and $n$-hexane adsorption; the second author used a SBA-15 silica [19], an "as-made" and an aluminium modified MCM-41 material to show that toluene and isopentane adsorption depend on the synthesis steps, hydrophilic nature and porous network-type of the matrix.

Adsorption of POPs usually occurs in water and the tested materials belonged to the MCM-41 family. Y.X. Zhao et al. [20] worked with surfactant-containing and surfactant-free MCM-41 type silica to adsorb mono-, di- and tri-chloroacetic acid while Di Renzo et al. [21] used trimethylbenzene in surfactant-containing MCM-41 material to adsorb chlorophenols. Vance et al. [22] studied tri- and tetra-chloroethylene adsorption in water using calcined MCM-41 with various amounts of structural aluminium sites.

As far as toxic metal adsorption is concerned, material surface needs, in most cases, to be chemically modified in order to favour metal-ligand interaction and enhance adsorption properties. In general, amino-functionalised silica surfaces are prepared to adsorb $\mathrm{Fe}^{3+}, \mathrm{Co}^{2+}, \mathrm{Ni}^{2+}$ and $\mathrm{Cu}^{2+}$ ions $[23,24]$ and thiol-modified surfaces are used for $\mathrm{Hg}^{2+}$ ions [24,25]. Sayari et al.[26] have synthesized pore expanded mesoporous silica containing an amine-type co-surfactant with the amino groups to which the cation can eventually coordinate, oriented towards the micellar core. In this case, no surface modification was performed.

Most of the cited works for adsorption of POPs used as-synthesized surfactantsilica mesophases that shows much superior performances than the surfactant-free samples [3]. This is due to the ability of the surfactant phase to solubilize organic molecules [21]. However, in this case, there is a possibility for displacement of surfactant molecules during the adsorption process in water. Some authors have proposed a surface modification of calcined MCM-41 samples by grafting hydrophobic 
groups [27]. This approach revealed to be quite effective for the adsorption of alkylphenols and alkylanilines [28].

So far, little attention was addressed towards the fate of the pollutant after its adsorption. In some cases [29], its degradation is performed by introduction of a photocatalytic $\mathrm{TiO}_{2}$ phase within the mesoporous silica host via the sol-gel process. One could also consider to recover the pollutant by washing and thus to regenerate the absorbent [30]. In that case, it is of prime importance to characterize the interactions that the pollutant may develop with the surface sites, in order to evaluate the possibility of later pollutant recovering and adsorbent recycling. Until now, almost no characterisation has been performed to better understand the pollutant/surface interactions. Inumaru et al. [31] concluded from IR data that alkyl-anilines are strongly hydrogen-bonded to silanol groups on the inorganic pore walls. However, this type of analysis can not be extended to any type of pollutants. In the same paper, the authors mention that no similar spectroscopic evidence could be obtained for nonylphenol.

This lack of knowledge regarding the pollutant/silica surface interactions prompted us to prepare organo-modified silicas with various organic groups at the pore surface, and to use high-resolution solid state NMR techniques to investigate the physical state of the organic pollutant in the various confined environments as well as the interactions it may develop with the modified silica surface.

Organo-modified mesoporous silicas have been prepared by one-pot synthesis based on co-condensation of tetraethoxysilane and organotriethoxysilane (R-TES). This approach, compared to the post-grafting method that was so far mostly used for pollutant adsorption, minimizes the number of synthetic steps and allows the introduction of a large number of organic functions which are uniformely distributed throughout the pore surface [32]. Various organic functions ( $R=$ phenyl, propyl, hexyl, 
hexadecyl) have been introduced to modulate the silica surface properties. They have been exploited to adsorb a modified chlorophenol in water, 2-chloro-4-methoxyphenol (CMP) and the adsorption performances will be discussed as a function of the $R$ groups. Then the behaviour and eventual interactions between the pollutant and the host matrix will be characterised by means of solid state Nuclear Magnetic Resonance (NMR), which revealed elsewhere $[6,33,34]$ to be a powerful technique to explore short range order interactions at the inorganic/organic interface in mesostructured silica-based materials. Knowledge of interactions between the adsorbed guest molecules and the host porous matrix is an important issue to evaluate the possibility for the materials to be further recycled and for the pollutant to be post-treated.

\section{Experimental}

\section{Material synthesis}

Materials have been synthesized according to the protocol introduced by Huo et al. [35]. A homogeneous solution of cetyltrimethylammonium bromide (CTAB, Aldrich) surfactant ( $0.3 \mathrm{~g}$ of CTAB were added to $15.9 \mathrm{~g}$ of water) was prepared at room temperature under highly acidic conditions $(6.1 \mathrm{~g}$ of $37 \% \mathrm{HCl}$ solution were added to $12.1 \mathrm{~g}$ of distilled water). Tetraethoxysilane (TEOS, Aldrich) was thus added (1.4 g) to obtain unmodified silica material (sample $\mathrm{SiO}_{2}$ ). Molar ratios were the following: TEOS/CTAB/ $\mathrm{H}_{2} \mathrm{O} / \mathrm{HCl}=1 / 0.12 / 130 / 9.2$. To prepare organo-modified silica samples, an organotriethoxyilane, $R$-TES, was added to the solution together with TEOS according to the following molar ratios: TEOS $/ R-\mathrm{TES} / \mathrm{CTAB} / \mathrm{H}_{2} \mathrm{O} / \mathrm{HCl}=$ 0.8/0.2/0.12/130/9.2, and with $R=\left(\mathrm{CH}_{2}\right)_{3}-,\left(\mathrm{C}_{6} \mathrm{H}_{5}\right)^{-},\left(\mathrm{CH}_{2}\right)_{6-},\left(\mathrm{CH}_{2}\right)_{16}$. The resulting samples were named: Propyl-SiO ${ }_{2}$, Phenyl-SiO ${ }_{2}, \mathrm{Hexyl}-\mathrm{SiO}_{2}, \mathrm{Hexadecyl}-\mathrm{SiO}_{2}$. Synthesis was performed under vigorous stirring during three hours. A white precipitate was then collected by filtration and dried at $100^{\circ} \mathrm{C}$ overnight. Surfactant was eliminated 
by washing with ethanol under reflux at $70^{\circ} \mathrm{C}$ for 5 hours in order to preserve the organic function.

The pollutant was 4-chloro-2-methoxyphenol (CMP, Aldrich) that absorbs UV radiation at $281 \mathrm{~nm}$ ( $\pi-\pi$ transition of the phenyl ring).

\section{Adsorption isotherms of pollutant}

The porous samples were previously degassed at $\mathrm{T}=100^{\circ} \mathrm{C}$ and $\mathrm{P}=10^{-2} \mathrm{bar}$ overnight and filled with nitrogen gas in order to prevent residual water within the pores, which could alter the measurement of the real mass of porous sample. Reaction beakers were filled with a known mass of degassed samples inside an atmosphere controlled glove box. The solution containing a known concentration of pollutant in distilled water was added afterwards. Concentration of CMP in water was controlled by means of UV absorption according to the Lambert-Beer law (Eq.1)

$\mathrm{A}=C \cdot \varepsilon \cdot l$

where $\mathrm{A}$ is the measured absorbance value, $C$ is the concentration in $\left[\mathrm{mol} \cdot \mathrm{L}^{-1}\right], \varepsilon$ is the coefficient of molar absorption in $\left[\mathrm{L} \cdot \mathrm{cm}^{-1} \cdot \mathrm{mol}^{-1}\right]$ and $l$ is the cell length in $[\mathrm{cm}]$. Lambert-Beer law is valid for absorbance values $\mathrm{A}<2$, which, for an $\varepsilon$ value typical of about $2000 \mathrm{~L} \cdot \mathrm{cm}^{-1} \cdot \mathrm{mol}^{-1}$ for CMP, gives a concentration range of pollutant in water $10^{-4}<C<10^{-3}$ mol.L ${ }^{-1}$ (See Figure S1 in supplementary material).

CMP solutions $(15 \mathrm{ml})$ with mesoporous powders $(50 \mathrm{mg})$ were placed in a water bath at $25^{\circ} \mathrm{C}$ during 3 hours; this time was determined by a trial-and-error procedure to be long enough to consider a thermodynamic equilibrium between adsorbed and desorbed pollutant to be reached. 
The powder was then filtered out and UV absorption of the filtered solution was used to quantify the amount of adsorbed pollutant according to the depletion method (equation 2) [36],

$$
\mathrm{A}_{\mathrm{s}}=\Delta A \cdot V \cdot l^{-1} \cdot \varepsilon^{-1} \cdot m^{-1}
$$

where $A_{s}$ is the specific molar adsorption (moles of pollutant per mass of powder introduced, [mol $\left.\left.\mathrm{g}^{-1}\right]\right), \Delta A$ is the difference between absorbance values of pollutant solution before and after the introduction of powder sample, $V$ is the employed volume of solution [L], $m$ is the mass of introduced powder sample [g].

\section{Characterization techniques}

X-ray diffraction (XRD) patterns have been recorded with a Philips PW 1830 diffractometer equipped with a $\mathrm{Cu}-\mathrm{K}_{\alpha}$ source $(\lambda=1.54 \AA)$, with a $0.02^{\circ}$ step and an acquisition time of $5 \mathrm{~s}$ per point. Nitrogen adsorption/desorption isotherms (77K) were recorded on a Micrometrics ASAP 2010 instrument. UV absorption experiments were done on a UVIKON XL using $1 \mathrm{~cm}$ length quartz cells.

Solid state NMR spectra were recorded on a Bruker AVANCE 300 spectrometer. Low temperature experiences were acquired with a Bruker BCU-X equipment. Listed below are the essential experimental parameters used in these experiments, where $v_{\mathrm{RF}}$ denotes the magnitudes of radio frequency field, NS the number of scans, $\mathrm{RD}$ the recycle delays between two scans. The cross polarization time $\left(\mathrm{t}^{\mathrm{CP}}\right)$ (when necessary) and the Magic Angle Spinning ( $v_{\text {MAS }}$ ) rate will be listed in the figure captions.

${ }^{1} H: v_{\mathrm{RF}}\left({ }^{1} \mathrm{H}\right)=55 \mathrm{kHz} ; 90^{\circ}$ pulse; $\mathrm{RD}=3 \mathrm{~s} ; \mathrm{NS}=8$.

${ }^{29} \mathrm{Si}: v_{\mathrm{RF}}\left({ }^{29} \mathrm{Si}\right)=50 \mathrm{kHz} ; 30^{\circ}$ pulse; $\mathrm{RD}=100 \mathrm{~s} ; \mathrm{NS}=544$. 
${ }^{1} \mathrm{H}^{29} \mathrm{Si} C P: v_{\mathrm{RF}}\left({ }^{1} \mathrm{H}\right)=50 \mathrm{kHz}$; tppm decoupling; RD = 2 s; NS = 2048.

${ }^{13} \mathrm{C}: v_{\mathrm{RF}}\left({ }^{13} \mathrm{C}\right)=58 \mathrm{kHz} ; \mathrm{CW}$ decoupling; $90^{\circ}$ pulse; $\mathrm{RD}=5 \mathrm{~s} ; 600<\mathrm{NS}<2000$.

${ }^{1} \mathrm{H}_{-}{ }^{13} \mathrm{C} \mathrm{CP}: v_{\mathrm{RF}}\left({ }^{1} \mathrm{H}\right)=55 \mathrm{kHz} ; \mathrm{CW}$ decoupling; RD = $2 \mathrm{~s} ; 1000<\mathrm{NS}<2000$.

${ }^{1} \mathrm{H}^{-13} \mathrm{C}$ INEPT: pumping delay, $\Delta 1=1.06 \mathrm{~ms}$; refocusing delay, $\Delta 2=0.92 \mathrm{~ms} ; \mathrm{v}_{\mathrm{MAS}}=14$

$\mathrm{kHz}\left(4 \mathrm{~mm}\right.$ rotor); $v_{\mathrm{RF}}\left({ }^{13} \mathrm{C}\right)=58 \mathrm{kHz}$; CW decoupling; $\mathrm{RD}=2 \mathrm{~s} ; \mathrm{NS}=1072$.

${ }^{1} \mathrm{H}^{13} \mathrm{C} C P$ HETCOR: $v_{\mathrm{RF}}\left({ }^{1} \mathrm{H}\right)=55 \mathrm{kHz}$; CW decoupling; RD = $2 \mathrm{~s} ; \mathrm{NS}=560 ; 50 t_{1}$

increments. Quadrature detection in t1 was realised using the States method [37].

All chemical shifts are referenced with external TMS. NMR spectra were modelled using the freely available DMFIT software [38].

\section{Results and discussion}

Figure. 1

Figure 1a) shows XRD patterns of as-synthesised silica and organo-modified silica samples. A unique diffraction peak at low angle is present for all samples, except Phenyl-SiO 2 . The absence of higher order peaks corresponds to a wormlike structure rather than a well-ordered 2D-hexagonal mesophase. Similar results were already reported [39]. Instead, two peaks with a shoulder at lower angles are present for Phenyl$\mathrm{SiO}_{2}$ and correspond to the (200), (210) and (211) peaks of a micellar cubic Pm3n structure with a cell parameter $a=77.2 \AA$. The retention of the ordering after the ethanol-washing step was verified by XRD (See Figure S2 in supplementary material). $\mathrm{N}_{2}$ adsorption/desorption isotherms recorded on surfactant-free materials are shown in Figure $1 b$ ). Isotherms of $\mathrm{SiO}_{2}, \mathrm{Hexyl}-\mathrm{SiO}_{2}$ and Hexadecyl-SiO${ }_{2}$ materials show a typeIV shape, which is typical of adsorption in the mesoporous range. Adsorption capacity 
decreases from pure silica material to organo-modified ones. BET specific surface area values (Table 1) decrease from about $1300 \mathrm{~m}^{2} / \mathrm{g}$ for $\mathrm{SiO}_{2}$ to about $300 \mathrm{~m}^{2} / \mathrm{g}$ for Hexyl$\mathrm{SiO}_{2}$ and Hexadecyl-SiO 2 while specific pore volume decreases from $0.95 \mathrm{~cm}^{3} / \mathrm{g}$ to 0.20. Phenyl-SiO 2 and Propyl-SiO 2 show a type-I isotherm where capillary adsorption occurs in the microporous range. Similar results were observed by Antonchshuk et al. [40], who suggested that accessibility to mesopores is affected by high adsorption capacity of organic groups and existence of narrow pores blocking the access to nitrogen gas molecules. Burleigh et al. [41] and Hamoudi et al. [42] confirmed these results.

\section{Table 1}

${ }^{29}$ Si MAS NMR spectra have already been reported for similar samples [39,43], showing that whatever the organic function $R$, the resulting amount of $\mathrm{T}$ units $\left(\mathrm{RSiO}_{1,5}\right)$ ranges from 20 to $25 \%$ with respect to the total Si sites (the theoretical amount is $20 \%$ ). The spectrum of the hexyl-SiO 2 sample after surfactant extraction is presented in Figure 2a, and indeed leads to a T content of $24 \%$. Once the presence of the organic groups is demonstrated, their localisation with respect to the pore surface is also another key issue for their applications as adsorbants. The reduction of the total pore volume (Table 1) when the size of the group increases is an indirect indication that a large part of them are certainly at the surface. Their presence at the silica/pore interface was directly demonstrated for the cubic Phenyl-SiO 2 material by employing two-dimensional solidstate NMR experiments [44,45].

\section{Figure 2}




\section{Figure 3}

Material resistance to the adsorption step in solution was verified by ${ }^{29} \mathrm{Si} \mathrm{CP}$ MAS experiments for $\mathrm{SiO}_{2}$, Phenyl-SiO 2 and Hexyl-SiO 2 . Figure 2 b) and c) show the results for the Hexyl-SiO 2 sample. The adsorption step does not remarkably modify the

${ }^{29} \mathrm{Si}$ CP-MAS spectra, so we conclude that the organo-modified matrix was not affected by adsorption procedure.

Adsorption isotherms of pollutant on mesoporous samples are shown in Figure 3. The plots of specific molar adsorption (eq. 2) versus pollutant concentration at equilibrium distinguish two families of adsorbents. Materials inside the gray circle, $\mathrm{SiO}_{2}$ and Hexadecyl-SiO 2 , show low values for the amount of adsorbed pollutant in the concentration range explored indicating, at a first glance, an unfavourable interaction between the matrix and the CMP. In reality, a clear distinction has to be made between $\mathrm{SiO}_{2}$ and Hexadecyl-SiO 2 samples. The first one, despite its extremely high specific surface available (1300 $\left.\mathrm{m}^{2} / \mathrm{g}\right)$, shows very poor CMP adsorption probably because of the hydrophilic nature of the material prepared under acidic synthesis conditions, instead of the usual basic conditions for the MCM-41 silica, whose efficiency with respect to organic pollutant adsorption was reported by Zhao et al.[19]. On the contrary, Hexadecyl-SiO ${ }_{2}$ material was observed to be highly hydrophobic showing very low mixing affinity with water solution. The powder stays at the water/air interface to minimize interactions between water and hexadecyl carbon chains present at the powder surface. Probability of meeting between CMP molecules and powder grains was then reduced by such a macroscopic phase separation behaviour. The second family of employed materials, Propyl-SiO 2 , Phenyl-SiO 2 and Hexyl-SiO 2 , showed higher CMP adsorption values. Isotherms indicate that the most performing material resulted to be 
Hexyl- $\mathrm{SiO}_{2}$, whose adsorption capacity is almost the double $\left(0.17 \mathrm{mmol} . \mathrm{g}^{-1}\right.$ versus 0.1 mmol.g $\mathrm{g}^{-1}$ ) at $\mathrm{C}_{\mathrm{eq}}=0.4 \mathrm{mmol} . \mathrm{L}^{-1}$ with respect to Phenyl-SiO 2 , the next best performing adsorbent.

Isotherms clearly show the critical influence of the surface nature with respect to the overall specific surface area. $\mathrm{Hexyl}-\mathrm{SiO}_{2}$ has a slightly lower surface area value (360 $\mathrm{m}^{2} / \mathrm{g}$ ) with respect to Propyl-SiO $2\left(545 \mathrm{~m}^{2} / \mathrm{g}\right)$ but its adsorption capacity increases at higher $\mathrm{C}_{\text {eq. }}$. Medium-length alkyl chains have certainly favourable interactions with CMP with respect to shorter chains (propyl) or even phenyl rings. Similar behaviour was already reported in literature [32]. Octyl groups were found to give better adsorbent performances than pentyl and dodecyl groups for alkylphenols and alkylanilines.

\section{Figure 4}

To get a better understanding of the pollutant behaviour within pores and its eventual interactions with the silica surface, solid state NMR investigations were undertaken on $\mathrm{SiO}_{2}$ the less performing sample and $\mathrm{Hexyl}-\mathrm{SiO}_{2}$ sample, the best performing adsorbent. In order to enhance the signal-to-noise ratio of the spectra, extra pollutant was externally added. Loading procedure was adapted from ref. [46] where about $0.5 \mathrm{~g}$ of material was impregnated several times with a solution of CMP in ethanol (65 mg/g). Ethanol was evaporated at $50^{\circ} \mathrm{C}$ between each impregnation.

Figure 4 shows ${ }^{1} \mathrm{H}$ MAS NMR spectra of $\mathrm{SiO}_{2}$ and Hexyl-SiO 2 recorded at different temperatures and with a moderate MAS rate $(5 \mathrm{kHz})$. At $298 \mathrm{~K}$, for both samples, the two signals at 6.6 and $3.6 \mathrm{ppm}$ are attributed, respectively, to phenyl ring and methoxy groups of CMP molecules. Their narrow FWHM, especially the one of the phenyl ring (50 Hz), indicate clearly high molecular mobility. The broader peak present 
around 5.5 ppm for both samples is due to silanol species involved in hydrogen bonding with water molecules $[34,47]$ and ethanol. The broad peak at $1.2 \mathrm{ppm}$ corresponds to the grafted hexyl chains in Hexyl- $\mathrm{SiO}_{2}$, while in $\mathrm{SiO}_{2}$, the small peak around 1 ppm is due to residual surfactant, incompletely removed by the solvent extraction procedure. When temperature is lowered down to $238 \mathrm{~K}$, all peaks are homogeneously broadened due to a reintroduction of the ${ }^{1} \mathrm{H}-{ }^{1} \mathrm{H}$ homonuclear dipolar coupling as a consequence of a reduced mobility of CMP molecules within the pores. Temperature effect over molecular mobility in confined media was used in similar systems to study, for instance, liquid-to-solid transitions [48]. However, from the ${ }^{1} \mathrm{H}$ line width evolution which is governed primarily by the extent of the homonuclear dipolar coupling, it is not possible to discriminate between the formation of a glassy or a crystalline state at lower temperature. The evolution of the ${ }^{13} \mathrm{C}$ line width described in the next paragraph will bring more information. Also the broadening of the CMP peaks seems less important at $258 \mathrm{~K}$ for $\mathrm{SiO}_{2}$ than for Hexyl-SiO 2 . However, the extensive overlap with other peaks, especially the peak due to the hexyl chains makes the analysis of linewidths difficult. In both samples, the transition between a quasi liquid-like state to a solid-like state occurs over a broad range of temperature characteristic of confined species.

\section{Figure 5}

To complete this study, ${ }^{13} \mathrm{C}$ MAS NMR spectra have been recorded at room temperature with three different ${ }^{13} \mathrm{C}$ detection methods that will help discriminate the $\mathrm{C}$ sites based on their mobility. This could reveal different populations of molecules, especially rigid ones whose ${ }^{1} \mathrm{H}$ NMR response could have been neglected in the analysis of the ${ }^{1} \mathrm{H}$ spectra due to extensive broadening. Indeed, once again, the CMP molecules in both samples show very similar behaviour; the spectra recorded on the $\mathrm{SiO}_{2}$ sample 
are presented as supplementary material (Figure S3) while the spectra of the Hexyl$\mathrm{SiO}_{2}$ sample will be discussed.

In the one-pulse ${ }^{13} \mathrm{C}$ MAS NMR spectrum (Fig. 5a), all carbon sites are detected. All the aromatic C peaks from CMP are observed between $\delta=100$ and 160 ppm; peaks at $\delta=125.6,144.8$ and $148.3 \mathrm{ppm}$ are due to quaternary carbons while peaks at $\delta=$ 112.6, 116.2 and $121.7 \mathrm{ppm}$ are due to the aromatic $\mathrm{CH}$ sites, as revealed later by the INEPT experiment. The peak at $\delta=56.5 \mathrm{ppm}$ is assigned to $\mathrm{OCH}_{3}$ group of CMP. The three intense peaks at 32.4, 23.3 and 14.3 ppm are due to the pendant hexyl chains grafted to silica surface $\left(^{\circ}\right)$. As for the remaining observed peaks at 60.4 and $17.9 \mathrm{ppm}$, they are due to ethoxy groups $\left(^{*}\right)$ that have been grafted to the surface during the surfactant removal procedure. Signal intensity integration gives a ratio of roughly 1 CMP molecule per 3.5 hexyl chain after impregnation. The ${ }^{13} \mathrm{C}$ CP MAS NMR spectrum based on through-space magnetization transfer via dipolar coupling favours detection of rigid protonated moieties. Thus, $\mathrm{CH}$ groups in totally rigid systems can be easily detected for very short contact times less than $100 \mu \mathrm{s}$. In the present system, peaks belonging to CMP are barely detected for $\mathrm{t}^{\mathrm{CP}}=500 \mu$ s and $\mathrm{t}^{\mathrm{CP}}$ has to be increased to $3 \mathrm{~ms}$ (Fig. 5b) for the peaks due to protonated $\mathrm{C}$ (aromatic $\mathrm{CH}$ and methoxy) to appear. One can however notice slight differences in the relative intensities of the hexylrelated peaks; especially the peak at 14 ppm that corresponds to the overlap of the $\underline{\mathrm{CH}}_{3}$ and Si- $\underline{\mathrm{CH}} \mathrm{H}_{2}$ signals is underestimated, because of the high mobility of the $\mathrm{CH}_{3}$ end group, which prevents a good polarisation transfer efficiency. The ${ }^{13} \mathrm{C}$ INEPT MAS NMR spectrum, based on through-bond magnetisation transfer, was also recorded following an approach developed by Alonso [49] (Fig. 5c). This experiment favours detection of mobile carbon sites directly bonded to protons, and brings thus complementary information with respect to CP experiment. Indeed, all the C sites of 
$\mathrm{CMP}\left(\mathrm{CH}\right.$ and $\left.\mathrm{O}-\mathrm{CH}_{3}\right)$ but the quaternary carbons (due to the lack of directly bonded H) are now very well detected, confirming attribution given in the one pulse spectrum (Fig. 5a). The $\mathrm{OCH}_{2}$ peak due to the ethoxy groups has disappeared, which suggests that these groups are truly grafted to the surface, and not simply adsorbed. Interestingly, three sharp peaks are detected for the hexyl chains with relative intensities and linewidths different from what could be seen in the previous spectra. They can be assigned to the sites exhibiting the highest mobility, e.g. $-\mathrm{CH}_{2}-\mathrm{CH}_{2}-\mathrm{CH}_{3}$. These experiments clearly demonstrate the rather high mobility that CMP molecules at room temperature can experience within the mesoporous hexyl-modified silica network. NMR spectra in Figure S3 in supplementary material show exactly the same behaviour of CMP molecule on the non-modified $\mathrm{SiO}_{2}$ substrate reinforcing ${ }^{1} \mathrm{H}$ NMR data. In both systems, CMP molecule experiences a very high mobility at RT.

\section{Figure 6}

Effect of mobility reduction of CMP at low temperature is confirmed in Figure 6 where ${ }^{13} \mathrm{C}$ CP MAS NMR spectra recorded on $\mathrm{SiO}_{2}$ sample are shown. In contrast with the spectra recorded at room temperature, for a contact time of $500 \mu$ s, efficiency of the CP technique is recovered. The signals from aromatic CMP sites are now detected, including the non-protonated sites with two broad signals between $150 \leq \delta \leq$ $130 \mathrm{ppm}$ and $130 \leq \delta \leq 100 \mathrm{ppm}$, which accounts for the two groups of carbons sites, identified in the ${ }^{13} \mathrm{C}$ MAS spectrum recorded at room temperature (Fig. 5a). In contrast with the ${ }^{1} \mathrm{H}$ case, the extensive peak broadening of the ${ }^{13} \mathrm{C}$ signals can only be related to the appearance of a distribution of sites. The adsorbed molecules tend to reach a disordered glassy state rather than a crystalline one. In addition, no signal of CMP 
carbons at $238 \mathrm{~K}$ can be detected at longer contact times due to short proton spin-lattice relaxation time in the rotating frame $\left(\mathrm{T}_{1} \rho\left({ }^{1} \mathrm{H}\right)\right)$.

High molecular mobility at room temperature is analogous to that already reported for benzoic acid [50] or ibuprofen [51] molecules encapsulated in MCM-41 type porous silica. Such behaviour suggests poor, if any, interaction between majority of CMP molecules and the silica framework. However, another minor population of CMP could interact more strongly with the surface, and be responsible for the detection of the weak peaks in the CP spectrum. In order to investigate this point, a two-dimensional ${ }^{1} \mathrm{H}$ ${ }^{13} \mathrm{C}$ CP-HETCOR experiment has been recorded with a 3 ms contact time at room temperature (Figure 7): the presence of cross-peaks between ${ }^{1} \mathrm{H}$ and ${ }^{13} \mathrm{C}$ signals will reveal spatial proximity between the corresponding species.

\section{Figure 7}

Despite the very large intensity of the peaks due to the hexyl chains with respect to the peaks due to CMP under CP conditions, the HETCOR spectrum reveals interesting features. The cross-peaks of E-type $\left(\delta^{1 \mathrm{H}}=0.9 \mathrm{ppm}\right.$ and $\delta^{13 \mathrm{C}}=32.5,23.4$ and 14.3 ppm for E1, E2 and E3 respectively) just indicate ${ }^{1} \mathrm{H}$-to- ${ }^{13} \mathrm{C}$ magnetization transfer within the $\mathrm{CH}_{2}$ groups of grafted hexyl chains. Similarly, $\mathrm{C}\left(\delta^{1 \mathrm{H}}=3.6 \mathrm{ppm} ; \delta^{13 \mathrm{C}}=59.9\right.$ ppm $)$ and $\mathrm{D}\left(\delta^{1 \mathrm{H}}=1.1 \mathrm{ppm} ; \delta^{13 \mathrm{C}}=17.9 \mathrm{ppm}\right)$ correspond to magnetization transfer within in, respectively, $\mathrm{OCH}_{2}$ and $\mathrm{CH}_{3}$ groups of grafted ethoxy species. For these groups, in addition, $\mathrm{C} 1\left(\delta^{1 \mathrm{H}}=1.1 \mathrm{ppm} ; \delta^{13 \mathrm{C}}=59.9 \mathrm{ppm}\right)$ and $\mathrm{D} 1\left(\delta^{1 \mathrm{H}}=3.6 \mathrm{ppm} ; \delta^{13 \mathrm{C}}=\right.$ $17.9 \mathrm{ppm})$ reveal intra-molecular magnetization transfers; from ${ }^{1} \mathrm{H}\left(\mathrm{C} \mathbf{H}_{3}\right) \rightarrow{ }^{13} \mathrm{C}\left(\mathrm{OCH}_{2}\right)$ for $\mathrm{C} 1$ from ${ }^{1} \mathrm{H}\left(\mathrm{OCH}_{2}\right) \rightarrow{ }^{13} \mathrm{C}\left(\mathrm{CH}_{3}\right)$ for D1 as illustrated in the scheme shown in Figure 5. As far as the pollutant molecule is concerned, the cross-peak $\mathrm{B}\left(\delta^{1 \mathrm{H}}=3.6 \mathrm{ppm} ; \delta^{13 \mathrm{C}}=\right.$ 
$56.3 \mathrm{ppm}$ ) indicates ${ }^{1} \mathrm{H}$-to- ${ }^{13} \mathrm{C}$ magnetization transfer within $\mathrm{OCH}_{3}$ groups, while crosspeaks $\mathrm{A}\left(\delta^{1 \mathrm{H}}=6.7 \mathrm{ppm} ; \delta^{13 \mathrm{C}}=112.6,116.2\right.$ and $\left.121.7 \mathrm{ppm}\right)$ refer to transfers occurring between the ${ }^{1} \mathrm{H}$ and ${ }^{13} \mathrm{C}$ sites of the aromatic ring. We observe then that, beside crosspeaks C1 and D1, all other peaks concern internal transfers between ${ }^{1} \mathrm{H}$ and ${ }^{13} \mathrm{C}$ sites of the same $\mathrm{CH}_{\mathrm{x}}$ entities. No evidence for dipolar interaction between CMP and surface sites is observed for a contact time of $3 \mathrm{~ms}$, neither for the methoxy group, nor for the phenyl ring. This contact time was chosen as being a good compromise to observe polarization transfer for systems having high molecular mobility [34].

Lack of strong interaction between CMP and the modified silica surface, despite its good adsorption properties, suggests an interesting new feature for the targeted application of these organically-modified mesoporous silica materials. Once the pollutant is captured, the material can undergo a washing step allowing the recycling of the host matrix and proper further treatment of the collected pollutant. Of course, one could wonder why pollutant-hexyl chains hydrophobic interactions do not seem strong enough to be proved by solid state NMR. These interactions of van der Waals-London type, though of discreet importance (forces between two induced dipoles may vary between 0.5 and $30 \mathrm{~kJ} / \mathrm{mol}$ ) are indeed responsible for greater CMP adsorption with respect to unmodified silica material surface covered with silanols and subject to weaker van der Waals-Debye forces whose energy range occurs between 0,02 and $0.5 \mathrm{~kJ} / \mathrm{mol}$. Lack of specific studies in literature on physisorption of hydrophobic molecules on organo-modified highly porous silica materials do not help us in such a task. Works dealing with adsorption of non-polar (benzene, cyclohexane) and polar (water) molecules on porous carbons [52], polar molecules on organo-modified porous silicas [53] and non-polar molecules on MCM-41 type of materials show quite a general 
consensus on the fact that an organic interface is suited to adsorb non-polar species. Since no specific study focuses on interactions between grafted organic groups on silicas (carbon materials are hydrophobic by nature and not by post-synthesis grafting) and non-polar molecules (though, one study tries to model benzene behaviour in SBA15 pores [54]), nothing is really known about the relative positioning between grafted organic functions and adsorbed molecules. Silica surface modification by organic pending groups is a matter of study by itself: for instance, Lesaint et al. [55] observed differences in $n$-propyl grafting rates depending on nature of material (MCM-41 or MCM-48) and grafting process. The way organic pending groups mutually dispose at silica surface (laying on surface or pointing inward the pore centre) is still an unclear issue. Studies performed on Self Assembled Monolayers [56] of grafted long alkyl chains on silica surface seem to show that an axial parallel is preferred to a tilted-type configuration. Nevertheless, this is true only for restricted zones of exposed surface where grafting density is the highest and given data only refer to long $\left(\mathrm{C}_{12}<\mathrm{C}_{18}\right.$ ) hydrophobic chains exhibiting larger interacting surfaces and not for short ones, as it occurs in our case. If grafted molecules are in an axial parallel configuration after surfactant removal, one could imagine adsorbed non-polar molecules located either between two grafted groups next to each other or at the centre of the pore, closer to the end of the grafted group itself. Inumaru proposed [28] that molecules rather locate between alkyl chains but in his case a specific interaction between the adsorbed molecule and alumina surface probably helped this type of adsorption. A final interpretation cannot be given here until model studies will not be done on similar systems. 


\section{Conclusions}

This paper concerns an environmental application of organo-modified mesoporous silica, prepared through a one-pot synthetic procedure. The adsorption properties towards an organic pollutant (here 4-Chloro-2-methoxyphenol, CMP) in water have been evaluated for various samples as a function of the surface groups. The objective was then to characterize by solid-state NMR the possible interactions that the adsorbed molecules may develop with the surface groups.

When the grafted functions are alkyl chains with short-to-medium length or phenyl groups, though specific surface area values are moderate $\left(300 \mathrm{~m}^{2} / \mathrm{g}\right)$, the resulting powdered samples adsorb much larger quantities of CMP than high specific surface area un-modified silica or highly hydrophobic hexadecyl-modified silica.

Combination of ${ }^{13} \mathrm{C}$ NMR techniques and ${ }^{1} \mathrm{H}$ NMR spectra recorded at lower temperatures, has been applied to two samples with opposite adsorption performances, the hexyl-modified silica and the un-modified silica : in both cases, it was clearly demonstrated that the CMP molecules experience, once adsorbed in the porous network, a high mobility. Additionally, the use of 2-dimensional ${ }^{1} \mathrm{H}-\mathrm{to}^{-13} \mathrm{C} \mathrm{CP}$ heteronuclear correlation (HETCOR) further emphasizes either the lack of strong interactions or long distances between the adsorbed pollutant molecules and the hexyl-modified silica surface, suggesting the possible integration of a recycling step of the final adsorbent material after a washing extraction procedure of the pollutant. We hope these results will open a way to a better understanding of interactions at organic-modified silica non-polar molecule interface, a domain where actual lack of studies does not help us into a complete understanding of our NMR with respect to adsorption isotherms results. 


\section{Acknowledgements}

Guillaume Laurent (LCMCP-UPMC) is strongly acknowledged for his technical assistance during the NMR experiments. Lionel Nicole (LCMCP-UPMC) is acknowledged for helpful discussions. Damien Bourgeois is acknowledged for help in the pollutant adsorption step.

\section{Notes and references}

[1] C.T. Kresge, M.E. Leonowicz, W.J. Roth, J.C. Vartuli and J.S. Beck, Nature 359 (1992) 710.

[2] G. J. de A.A Soler-Illia, C. Sanchez, B. Lebeau, J. Patarin, Chem. Rev. 102 (2002) 4093.

[3] D. Zhao, P. Yang, Q. Huo, B.F. Chmelka, G.D. Stucky, Curr. Op. Sol. St. Mater. Sci. 3 (1998) 111.

[4] Y. Lu, H. Fan, A. Stump, T.L. Ward, T. Rieker, C.J. Brinker, Nature 398 (1999) 223; N. Baccile, D. Grosso, C. Sanchez, J. Mater. Chem. 13 (2003) 3011.

[5] C.J. Brinker, Y. Lu, A. Sellinger, H. Fan, Adv. Mater. 11 (1999) 579; D. Grosso, F. Babonneau, P.-A Albouy, H. Amenitsch, A.R. Balkenende, A. Brunet-Bruneau, J. Rivory, J. Chem. Mater. 14 (2002) 931.

[6] N.A. Melosh, P. Lipic, F.S. Bates, F. Wudl, G.D. Stucky, G.H. Fredrickson, B.F. Chmelka, Macromolecules 32 (1999) 4332.

[7] A. Sayari, Chem. Mater. 8 (1996) 1840.

[8] A. Corma, Chem. Rev. 97 (1997) 2373.

[9] F. Goettmann, D. Grosso, F. Mercier, F. Mathey, C. Sanchez, Chem. Comm. 10 (2004) 1240.

[10] U. Ciesla, F. Schuth, Micro. Meso. Mater. 27 (1999) 131. 
[11] M. Vallet-Regi, A. Ramila, R.P. del Real, J. Perez-Pariente, Chem. Mater. 13 (2001) 308.

[12] L. Nicole, C. Boissière, D. Grosso, P. Hesemann, J. Moreau, C. Sanchez, Chem. Comm. (2004) 2312.

[13] A.R. Balkenende, F.K. de Theije, J.C.K. Kriege, Adv. Mater. 15 (2003) 139.

[14] S. L. Burkett, S. D. Sims, S. Mann, Chem. Comm. (1996) 1367.

[15] D. J. Macquarrie, Chem. Comm. (1996) 1961.

[16] http://ec.europa.eu/environment/chemicals/reach/reach_intro.htm

[17] X.S. Zhao, Q. Ma, G.Q. Lu, Energy \& Fuels 12 (1998) 1051.

[18] D.P Serrano, G. Calleja, J.A. Botas, F.J. Gutierrez, Ind. Eng. Chem. Res. 43 (2004) 7010.

[19] D. Zhao, Q. Huo, J. Feng, B.F. Chmelka, G.D. Stucky, J. Am. Chem. Soc. 120 (1998) 6024.

[20] Y.X. Zhao, M.Y. Ding, D.P. Chen, Anal. Chim. Acta 542 (2005) 193.

[21] K. Hanna, I. Beurroies, R. Denoyel, D. Desplantier-Giscard, A. Galarneau, F. Di Renzo, J. Coll. Inter. Sci. 252 (2002) 276.

[22] H. Zhao, K.L. Nagy, J.S. Waples, G.F. Vance, Environ. Sci. Tech. 34 (2000) 4822.

[23] H. Yoshitake, T. Yokoi, T. Tatsumi, Chem. Mater. 15 (2003) 1713.

[24] A.M. Liu, K. Hidajat, S. Kawi, D.Y. Zhao, Chem. Comm. (2000) 1145.

[25] V. Antochshuk, O. Olkhovyk, M. Jaroniec, I.-S. Park, R. Ryoo, Langmuir 19 (2003) 3031.

[26] A. Sayari, S. Hamoudi, Y. Yang, Chem. Mater. 17 (2005) 212.

[27] K. Inumaru, J. Kijoto, S. Yamanaka, Chem. Comm. (2000) 903.

[28] K. Inumaru, Y. Inoue, S. Kakii, T. Nakano, S. Yamanaka, Phys. Chem. Chem. Phys. 6 (2004) 3133. 
[29] E.P. Reddy, B. Sun, P.G. Smirniotis, J. Phys. Chem. B 108 (2004) 17198; T. Kasahara, K. Inumaru, S. Yamanaka, Micro. Meso. Mater 76 (2004) 123

[30] A.Yamaguchi, T. Awano, K. Oyaizu, M. Yuasa, J. Nanosci. Nanotech. 6 (2006) 1689

[31] K. Inumaru, Y. Inoue, S. Kakii, T. Nakano, S. Yamanaka, Phys. Chem. Chem. Phys. 6 (2004) 3133.

[32] A. Stein, B. J. Melde, R. C. Schroden Adv. Mater. 12 (2000) 1403

[33] N. Baccile, J. Maquet, F. Babonneau, C. R. Chimie 9 (2006) 478.

[34] N. Baccile, G. Laurent, C. Bonhomme, P. Innocenzi, F. Babonneau, Chem. Mater. 19 (2007) 1343.

[35] Q. Huo, D.I. Margolese, G.D. Stucky, Chem. Mater. 8 (1996) 1147

[36] K. Hanna, R. denoyel, I. Beurroies, J.P. Dubès, Coll. Surf. A: Physicochem. Eng. Asp. 254 (2005) 231.

[37] D.J. States, R.A. Haberkorn, D.J. Ruben, J. Magn Reson. 48 (1982) 286.

[38] D. Massiot, F. Fayon, M. Capron, I. King, S. Le Calve', B. Alonso, J.-O. Durand, B. Bujoli, Z. Gan, G. Hoatson, Magn. Reson. Chem. 40 (2002) 70.

[39] F. Babonneau, L. Leite, S. Fontlupt, J. Mater. Chem. 9 (1999) 175.

[40] V. Antonchshuk, M. Kruk, M. Jaroniec, J. Phys. Chem. B . 107 (2003) 11900.

[41] M.C. Burleigh, M.A. Markowitz, M.S. Spector, B.P. Gaber, J. Phys. Chem. B . 105 (2001) 9935.

[42] S. Hamoudi, Y. Yang, I. L. Moudrakovski, S. Lang, A. Sayari, J. Phys. Chem. B . 105 (2001) 9118.

[43] V. Goletto, V. Dagry, F. Babonneau, Mater. Res. Soc. Symp. Proc. 576 (1999) 229.

[44] V. Goletto, M. Imperor, F. Babonneau, St. Surf. Sci. Catal. 135 (2001) 1129.

[45] V. Goletto, PhD thesis, University Pierre et Marie Curie - Paris 6, Paris, France. 
[46] C. Charnay, S. Bégu, C. Tourné-Peteilh, L. Nicole, D.A. Lerner, J.M. Devoisselle, Eur. J. Pharm. Biopharm. 57 (2004) 533.

[47] J. Trebosc, J. W. Wiench, S. Huh, V. S.-Y. Lin, M. Pruski, J. Amer. Chem. Soc. 127 (2005) 3057.

[48] Y. Xia, G. Dosseh, D. Morineau, C. Alba-Simionesco J. Phys. Chem. B 110 (2006) 19735

[49] B. Alonso, D. Massiot, J. Magn. Res 163 (2003) 347.

[50] F. Babonneau, L. Yeung, N. Steunou, C. Gervais, A. Ramila, M. Vallet-Regi, J. Sol-gel Sci. Tech. 31 (2004) 219.

[51] T. Azaïs, C. Tourné-Péteilh, F. Aussenac, N. Baccile, C. Coelho, J.-M. Devoisselle, F. Babonneau, Chem. Mater. 18 (2006) 6382.

[52] a) F. Haghseresht,, S. Nouri, J. J. Finnerty,G. Q. Lu, J. Phys. Chem. B 106 (2002) 10935; b) A.M. Slasli , M. Jorge , F. Stoeckli , N.A. Seaton Carbon 41 (2003) 479

[53] T. Kimura, M. Suzuki, M. Maeda, S. Tomura, Micro. Meso. Mater., 95 (2006) 213

[54] E. Gedat, A. Schreiber, J. Albrecht, Th. Emmler, I. Shenderovich, G. H. Findenegg, H.-H. Limbach, G. Buntkowsky, J. Phys. Chem. B 106 (2002) 1977 [55] C. Lesaint, B. Lebeau, C. Marichal, J. Patarin, Micro. Meso. Mater. 83 (2005) 76 [56] A. Ulman Adv. Mater. 2 (1990) 573 


\section{Figures}

Figure 1 (a) X-Ray diffraction patterns of templated silica and organosilica samples; (b) $\mathrm{N}_{2}$ adsorption/desorption isotherms recorded on the surfactant-free samples. Numeric codes are the following: 1/SiO 2 ; $/ \mathrm{Phenyl}_{-} \mathrm{SiO}_{2} ; 3 / \mathrm{Propyl}_{-} \mathrm{SiO}_{2} ; 4 / \mathrm{Hexyl}-\mathrm{SiO}_{2}$; 5/Hexadecyl-SiO 2

Figure $2:{ }^{29} \mathrm{Si}$ MAS-NMR (a) and ${ }^{29} \mathrm{Si}$ CP MAS-NMR (b) spectra of the porous washed Hexyl-SiO 2 sample before adsorption. ${ }^{29} \mathrm{Si} \mathrm{CP}$ MAS-NMR spectrum (c) after pollutant adsorption. $\left(v_{\mathrm{MAS}}=5 \mathrm{kHz} ; \mathrm{t}^{\mathrm{CP}}=3 \mathrm{~ms}\right)$.

Figure 3 4-Chloro-2-methoxyphenol (CMP) adsorption isotherms $\left(\mathrm{T}=25^{\circ} \mathrm{C}\right)$ in water. Results are given in mol.g ${ }^{-1}$ (moles of pollutant per gram of powder)

Figure $4{ }^{1} \mathrm{H}$ MAS NMR ( $v_{\text {MAS }}=5 \mathrm{kHz}$ ) spectra of (I) $\mathrm{SiO}_{2}$ and (II) $\mathrm{Hexyl}-\mathrm{SiO}_{2}$ after CMP adsorption performed at a) $298 \mathrm{~K}$, b) $258 \mathrm{~K}$ and c) $238 \mathrm{~K}$.

Figure 5 Comparison between ${ }^{13} \mathrm{C}$ MAS NMR spectra of Hexyl-SiO 2 sample after CMP adsorption. (a) one-pulse experiment; (b) $\mathrm{CP}$ experiment $\left(\mathrm{t}^{\mathrm{CP}}=3 \mathrm{~ms}\right.$, $\mathrm{v}_{\mathrm{MAS}}=5$ kHz); (c) INEPT spectrum.

Figure $6{ }^{13} \mathrm{C}$ CP-MAS spectra of $\mathrm{SiO}_{2}$ sample after CMP adsorption recorded at $\mathrm{T}=$ $298 \mathrm{~K}\left(\mathrm{t}^{\mathrm{CP}}=3 \mathrm{~ms}\right.$ and $\left.500 \mu \mathrm{s}\right)$ and $238 \mathrm{~K}\left(\mathrm{t}^{\mathrm{CP}}=500 \mu \mathrm{s}\right)$ with $v_{\mathrm{MAS}}=5 \mathrm{kHz}$ 
Figure $7{ }^{1} \mathrm{H}-{ }^{13} \mathrm{C}$ HETCOR experiment for Hexyl-SiO 2 sample recorded at room temperature $\left(v_{\mathrm{MAS}}=14 \mathrm{kHz} ; \mathrm{t}^{\mathrm{CP}}=3 \mathrm{~ms}\right)$ 
Table 1 BET surface area and total pore volumes of the samples. 


\section{Supplementary Information}

Figure S1. Determination of molar adsorption coefficient for CMP molecule in water at room temperature.

Figure S2. X-Ray diffraction patterns of ethanol-washed silica and organo-modified mesostructured silica samples.

Figure S3. Comparison of ${ }^{13} \mathrm{C}$ MAS NMR spectra of $\mathrm{SiO}_{2}$ sample after CMP adsorption. (a) one-pulse experiment; (b) CP experiment recorded with a contact time of $3 \mathrm{~ms}\left(v_{\mathrm{MAS}}=5 \mathrm{kHz}\right)$; (c) INEPT spectrum. 